\title{
MANAGEMENT OF SYMPTOMATIC LATENT NYSTAGMUS
}

\author{
CHRISTOPHER LIU ${ }^{1}$, MICHAEL GRESTY ${ }^{2}$ and JOHN LEE ${ }^{1}$ \\ London
}

\begin{abstract}
SUMMARY
Most patients with latent nystagmus are asymptomatic and do not require treatment. We discuss the management by botulinum toxin injection and surgery of five cases of latent nystagmus in which the patients suffered loss of visual acuity on certain manoeuvres as a consequence of an exacerbation of the nystagmus amplitude. The importance of eye movement recordings for accurate diagnosis is stressed and the investigative role of botulinum toxin injection is discussed. Extraocular muscle surgery is helpful in some cases of symptomatic latent nystagmus.
\end{abstract}

The term 'latent nystagmus' is commonly used in clinical practice to refer to a nystagmus which appears or markedly enhances when one or other eye is covered. The majority of latent nystagmuses encountered are associated with infantile strabismus or marked phoria. In these cases the nystagmus provoked by cover always beats away from the occluded eye (Fig. 1). ${ }^{1}$ Careful analysis of the nystagmus waveform reveals two distinct types. ${ }^{2,3}$ The first of these is referred to as $\mathrm{LN}$ and is characterised by a slow phase waveform which has a decelerating velocity (Fig. 1). LN is characteristically dampened in adduction and worsened in abduction according with Alexander's law. ${ }^{4}$ The second variety of latent nystagmus associated with strabismus is referred to as $\mathrm{CN}$ and is possibly the more common. ${ }^{3} \mathrm{CN}$ is characterised by a slow phase waveform which has exponentially increasing velocities as is typical of 'congenital nystagmus'. Latent nystagmus associated with strabismus is always bilateral but the amplitude of the beats may be very asymmetrical depending on which eye is covered. ${ }^{5}$ It may be glimpsed under cover that the occluded eye moves synchronously with the viewing eye (Fig. 1).

Latent nystagmus has a strong association with child-

From: 'Moorfields Eye Hospital, City Road, London EC1V 2PD, UK; ${ }^{2}$ MRC Human Movement and Balance Unit, Section of NeuroOtology, Institute of Neurology, National Hospital for Neurology and Neurosurgery, Queen Square, London WC1N 3BG, UK.

Correspondence to: Mr. C. S. C. Liu, FCOphth, Department of Ophthalmology, Addenbrooke's Hospital, Hills Road, Cambridge CB2 2QQ, UK. hood squint ${ }^{2,3,6,7}$ and dissociated vertical deviation (DVD) ${ }^{8}$ It is a benign condition and is not associated with neurological diseases. ${ }^{2}$ Under most circumstances, the demonstration of latent nystagmus is of trivial importance and the majority of patients are asymptomatic. The main reported problem with latent nystagmus is in the assessment of monocular visual acuity, ${ }^{9}$ especially in children with strabismus. ${ }^{10,11} \mathrm{~A}$ further variety of latent nystagmus may be encountered in which the direction of nystagmus beat is independent of the laterality of covering. In our experience patients with this variety are rare and on analysis have turned out to be cases of congenital nystagmuses. They are not accompanied by strabismus.

We report five patients with latent nystagmus all of whom had problems directly related to their nystagmus. Three of these patients had LN, one had latent $\mathrm{CN}$ and the fifth had congenital nystagmus. All cases except case 1 had eye movement recordings, i.e. electronystagmography (ENG) and/or infrared corneal reflection oculography.

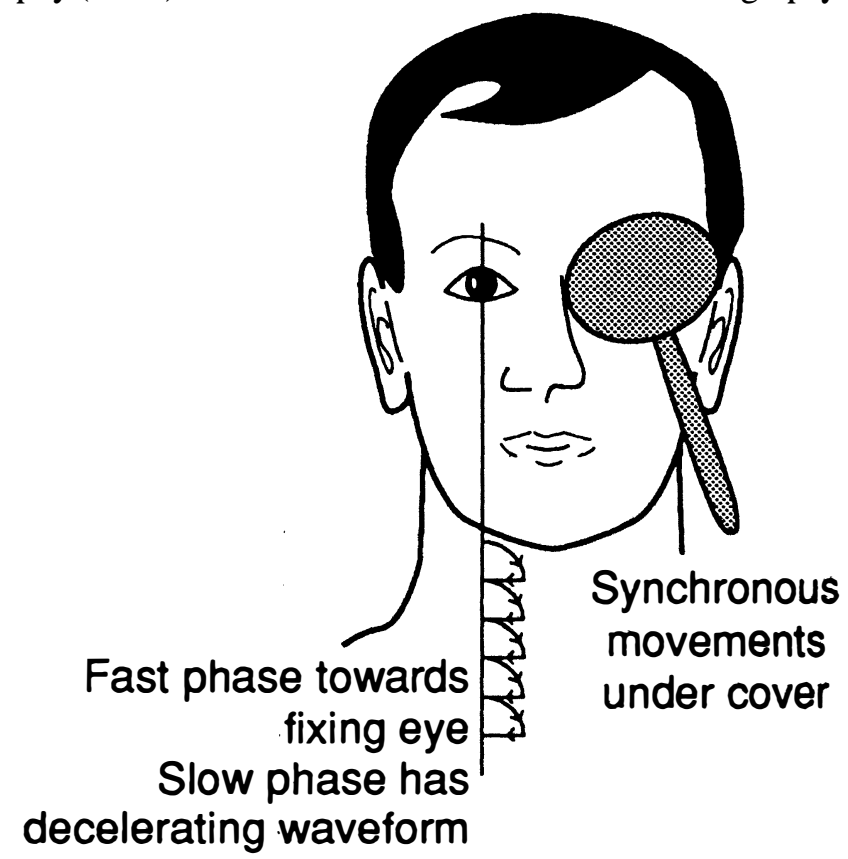

Fig. 1. The characteristic waveform of $L N$. The occluded eye moves synchronously. 


\section{CASE REPORTS}

\section{Case 1}

B.H. was a 44-year-old female teacher who lost her right eye in infancy as a result of retinoblastoma. From childhood, she had noticed that her vision improved on right gaze, with oscillopsia in the primary position. The improvement in vision was significant. Looking straight ahead she could see $6 / 24$ only, but with a large face turn to the left she could see $6 / 6$. Her eye was otherwise normal. She was suffering from the effects of unmasked $\mathrm{LN}$ in her remaining eye. ${ }^{12,13}$ Surgery to her horizontal muscles was advised by the referring surgeon but the patient was worried about an operation on her only eye.

We injected her left medial rectus (MR) muscle with botulinum toxin (BTX) in October 1986. Vision in the primary position improved to $6 / 6$. She felt this was of great benefit to her as she no longer had to live with an unsightly and inconvenient head posture. She eventually decided to proceed with surgical treatment in July 1987 (LMR $-5 \mathrm{~mm}, \mathrm{LR}+7 \mathrm{~mm}$ ). By September 1987 she could see $6 / 9+$ with or without a head posture. She was discharged soon after. She wrote to us to say that she remains very pleased with her operation (May 1992).

\section{Case 2}

S.B. was a healthy 19 -year-old man who sought entry to the Army but was rejected because of poor monocular visual acuity in his right eye, as this impaired his ability to sight a rifle. He has a history of a squint in childhood. His binocular visual acuity was $6 / 6$, but monocular vision with his right eye was $6 / 36$ only with markedly asymmetrical LN. This improved in adduction to 6/18. As his lifetime ambition was to join the Army, he presented to us with a request to improve his right monocular acuity.

An injection of BTX to his right MR (October 1990) increased his right divergent squint (RXT) but caused no diplopia. Vision in the primary position improved to 6/9. He accepted surgery and he had a Faden procedure on his right MR in January 1991. This operation was chosen in preference to a recess/resect procedure as we did not want to worsen his strabismus. He saw 6/6 with his right eye without a face turn immediately post-operatively. At 6 months post-operatively he saw $6 / 18$ without a head posture, and 6/6p with a slight face turn. This effect was sustained 16 months after surgery (Fig. 2).

\section{Case 3}

A.M. was a 67-year-old man who gave a history of a 'wobbly right eye with poor vision' for as long as he could remember. He came to us for an unrelated problem but was also worried about losing his left eye. He enquired as to whether there was anything we could do to improve his right eye. He had a small right divergent squint and he exhibited grossly asymmetrical $\mathrm{LN}$ which was worse on the right (ENG not shown but similar to case 2). Vision with both eyes open was $6 / 12+$ but monocular right vision was $6 / 60$ with gross oscillopsia and left $6 / 12$ with slight oscillopsia. To investigate the visual potential of his right eye we injected his right MR with BTX.

Follow-up revealed greatly reduced nystagmus but the monocular vision improved only very slightly to $6 / 36$ without oscillopsia and was not helped by a pin hole or by refraction. The poor vision was therefore due to amblyopia rather than to oscillopsia. He was informed about this and he accepted that the amblyopia was untreatable at his age. ${ }^{5,14}$ Furthermore, the toxin injection had increased his angle of exotropia, moving his right eye out of his suppression scotoma. He had to wear a base in Fresnel prism over his right spectacle lens to relieve diplopia but he was reassured that this would eventually disappear. No surgery was offered.

\section{Case 4}

P.S. was a healthy 25 -year-old builder. He complained of poor vision when driving at night which was helped by adopting a head posture. He had 6/9 vision in either eye and 6/6 binocularly in normal clinic conditions. Even under these circumstances he claimed that he could see more clearly when adopting a head tilt and face turn to the right, although this could not be shown with Snellen acuities. Clinically, he exhibited marked latent nystagmus with fine manifest horizontal and rotary nystagmus also present at slit lamp examination. His eyes were straight and otherwise normal.

His eye movements were studied both in light and in darkness using ENG and infrared video recordings. Although he exhibited an increase in the amplitude of his
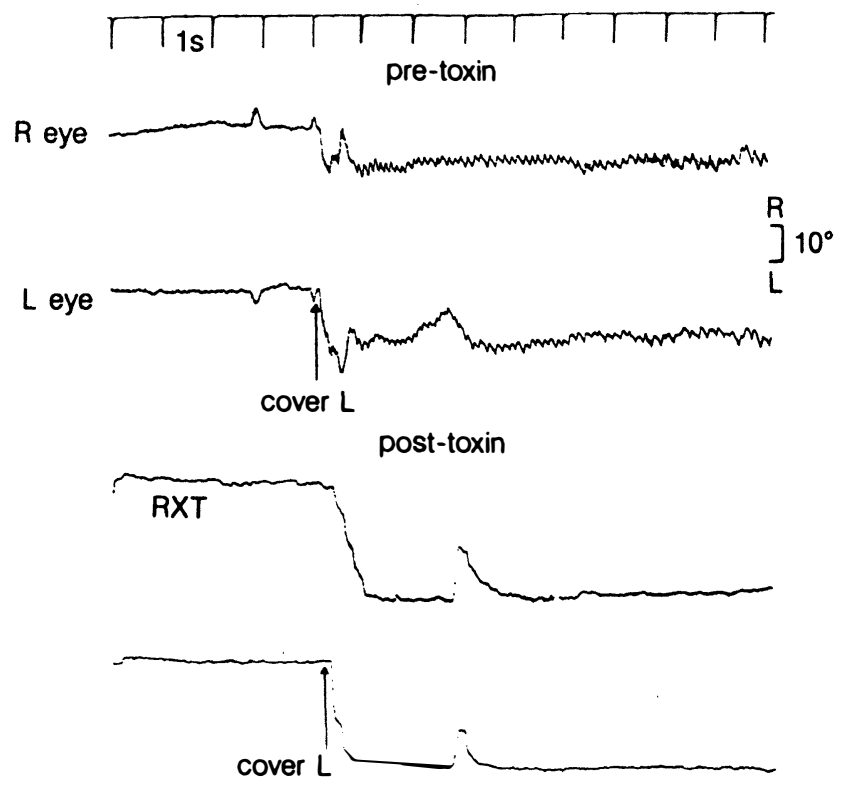

Fig. 2. Pre-and post-toxin ENGs of case 2. Pre-toxin: With both eyes open, the eyes are shown to be still. On covering the left eye, nystagmus beating towards the right (fixing) eye is shown. Note the decelerating slow wave. Post-toxin: The right eye is divergent (RXT) and with both eyes open the eyes are shown to be steady as before. On covering the left eye, the divergent right eye takes up fixation and the eyes remain still. The post-surgical recording (not shown) is similar to the posttoxin trace. 


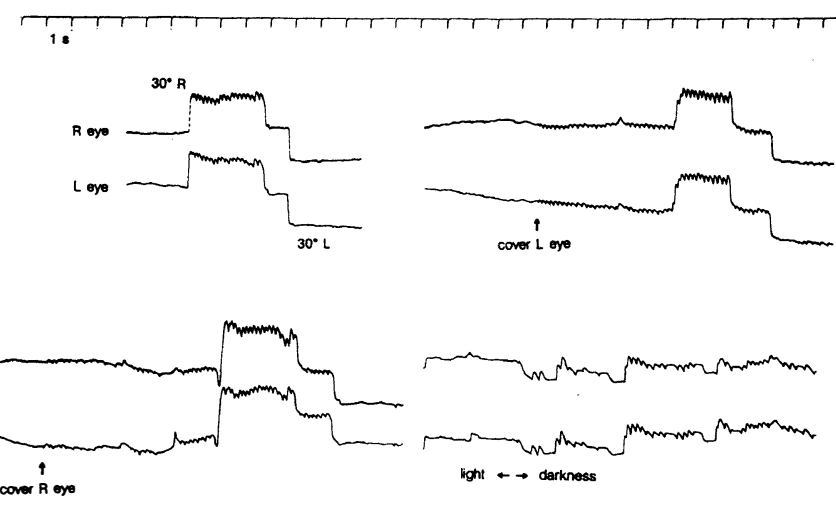

Fig. 3. ENG of case 4 with both eyes open looking $30^{\circ}$ right, straight ahead and $30^{\circ}$ left in normal room lighting (top left); same with left eye covered (top right); same with right eye covered (bottom left); and with both eyes open in light and in darkness (bottom right).

nystagmus on covering either eye, the waveform of his nystagmus was characteristic of that of congenital nystagmus (CN): the eyes always beat rightwards (as opposed to beating towards the fixing eye) and the slow phase had an accelerating velocity. Binocularly and with good lighting the nystagmus was confined to right gaze (Fig. 3, top left).

With covering of either the right (Fig. 3, bottom left) or the left eye (Fig. 3, top right) and with low levels of illumination, including total darkness (Fig. 3, bottom right), the right beating nystagmus extended to all eye positions being of minimal amplitude on left gaze. The patient was offered an Anderson-Kestenbaum type procedure to shift his null zone and improve his compensatory head posture but he decided against it. ${ }^{7,15-17}$

\section{Case 5}

C.R.W. was a 6-year-old girl with a history of a variable divergent squint from 2 weeks of age. She had poor distance vision (6/24 right and 6/18 left, corrected) and had problems with reading despite better near acuities (6/9 either eye at $0.33 \mathrm{~m}, 6 / 6$ both eyes open at $10 \mathrm{~cm}$, reduced Snellen). Albinism was suggested by the absence of foveal pits and by visual evoked potentials. She exhibited latent nystagmus clinically and being albino she would almost certainly be a case of $\mathrm{CN}$. She frequently made large involuntary saccades during refixation movements and target tracking, taking her off target. An example of these

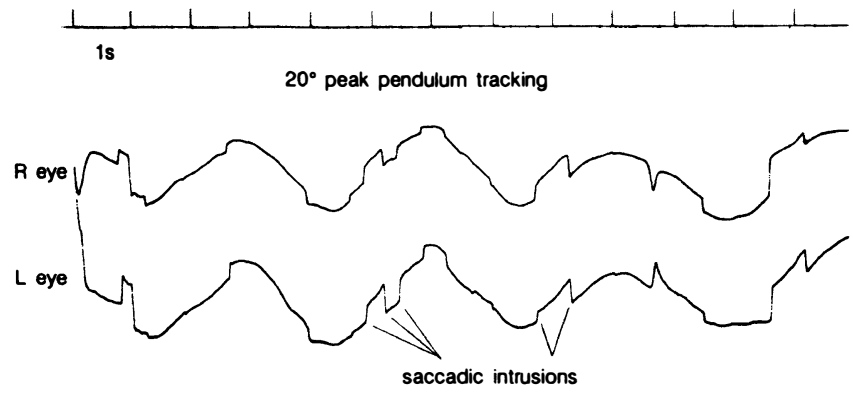

Fig. 4. ENG of smooth pursuit eye movement of case 5 demonstrating intact binocular pursuit interrupted by saccadic intrusions. saccadic intrusions is shown during binocular smooth pursuit (Fig. 4).

We believe this to be a factor in her reading difficulty. We have seen 30 cases of latent nystagmuses and these saccadic intrusions were present in approximately $15 \%$ of cases. ${ }^{4}$ These involuntary saccadic movements could not be abolished and we were unable to help this child beyond giving her spectacles. ${ }^{17,18}$

\section{DISCUSSION}

Most patients with LN are asymptomatic and do not require treatment. BTX injection into the MR muscle has an investigative role in some symptomatic cases (cases 1 to 3). Because the MR muscle is paralysed, more adduction innervation is required to bring the eye into the primary position. This has the effect of stabilising the nystagmus as LN is dampened in adduction.

By abolishing LN, BTX allows accurate assessment of the visual potential of the beating eye, including an accurate refraction. A method in common usage for the measurement of monocular vision involves fogging the non-fixing eye with a 'plus' lens. However, a lens strong enough to fog adequately also brings out the LN. ${ }^{10,19}$ Other methods involve the use of haploscopic devices. ${ }^{10,11,20} \mathrm{We}$ do not advocate routine use of BTX for the measurement of monocular visual acuity.

The effect of toxin simulates that of surgery and this would help both the patient and the surgeon to decide whether to proceed with surgery. BTX should not be viewed as a therapeutic tool as its effect is temporary, with its nystagmus-dampening effect more short lived than its squint-inducing effect. ${ }^{17}$ The choice of surgery lies between medial rectus recession with or without a Faden suture and a recess/resect procedure depending on whether strabismus is present. In a monocular situation with a prosthesis occupying the fellow socket, a recess/ resect procedure would be most effective (case 1). In these circumstances there is no need to worry about diplopia and inducing a squint. Although we have only a small number of patients, it is probable that a successful outcome with diagnostic toxin injection will predict surgical success.

Surgery to the horizontal extraocular muscle(s) should only be considered if an improvement in head posture, vision (oscillopsia and visual acuity) or both can be expected. The surgeon must bear in mind that post-operative diplopia may develop and pre-operative diagnostic BTX will predict whether this may become a problem. The efficacy of surgery for nystagmus may decline with time but further surgery is effective and may be undertaken if necessary. ${ }^{17}$

Patients exhibiting latent nystagmus should have eye movement recordings before BTX and surgery. ${ }^{21}$ Although typical cases are easy to diagnose clinically, some cases can be confusing. Case 4 illustrates this point. Clinically, he exhibited latent nystagmus, but purists would classify him as $\mathrm{CN}$ with a latent component according to his eye movement recordings. ${ }^{3}$ This, of course, has implications in the choice of therapy. ${ }^{7}$ 
We wish to thank Dr. C. H. Lau for his help.

Key words: Botulinum toxin, Electronystagmography, Latent nystagmus, Oscillopsia, Saccadic intrusions, Visual acuity.

\section{REFERENCES}

1. Dell'Osso LF, Abel LA, Daroff RB. Latent/manifest latent nystagmus reversal using an ocular prosthesis: implications for vision and ocular dominance. Invest Ophthalmol Vis Sci 1987;28:1873-6.

2. Dell'Osso LF, Schmidt D, Daroff RB. Latent, manifest latent, and congenital nystagmus. Arch Opthalmol 1979;97: 1877-85.

3. Dell'Osso LF. Congenital, latent and manifest latent nystagmus: similarities, differences and relation to strabismus. Jpn J Ophthalmol 1985;29:351-68.

4. Gresty MA, Metcalfe T, Timms C, Elston JS, Lee JP, Liu CSC. Neurology of latent nystagmus. Brain 1992;115: 1303-21.

5. von Noorden GK, Avilla C, Sidikaro Y, LaRoche R. Latent nystagmus and strabismic amblyopia. Am J Ophthalmol 1987;103:87-9.

6. Goddé-Jolly D, Larmande A. Les nystagmus, vol. 1. Paris: Masson, 1973:417ff.

7. Spielmann A. Différences électro-nystagmographiques entre nystagmus congénitaux essentiels et nystagmus congénitaux manifeste-latents. Bull Soc Opht France 1986;86: 1473-9.

8. Anderson JR. Latent nystagmus and alternating hyperphoria. Br J Ophthalmol 1954;38:217-31.

9. Dorman K. Binocular versus monocular acuity in a patient with latent nystagmus. J Am Opt Assoc 1982;53:485-6.

10. Moore DM. Visual acuity assessment in latent nystagmus.
In: Lenk-Schäfer $\mathbf{M}$, editor. Orthoptic horizons. Transactions of the Sixth International Orthoptic Congress, Harrogate, UK, 1987:487-91.

11. von Noorden GK. Binocular vision and ocular motility. Theory and management of strabismus. 4th ed. St Louis: Mosby, 1990:446.

12. Helveston EM, Pinchoff B, Ellis FD, Miller K. Unilateral esotropia after enucleation in infancy. Am J Ophthalmol 1985;100:96-9.

13. W Hasse V. Zur operativen Therapie der Kopffehlhaltung infolge Nystagmus bei Monophthalmus. Klin Monatsbl Augenkeilkd 1971;158:35-41.

14. Simonz HJ. The effect of prolonged monocular occlusion on latent nystagmus in the treatment of amblyopia. Doc Ophthalmol 1989;72:375-84.

15. Anderson JR. Causes and treatment of congenital eccentric nystagmus. Br J Ophthalmol 1953;37:267-80.

16. Kestenbaum A. Nouvelle opération du nystagmus. Bull Soc Ophthalmol Fr 1953;599-602.

17. Lee JP. Surgical management of nystagmus: Eye 1988;2: 44-7.

18. Zubcov AA, Reinecke RD, Gottlob I, Manley DR, Calhoun JH. Treatment of manifest latent nystagmus. Am J Ophthalmol 1990;110:160-7.

19. Esser J, Kolling G. Der Einfluss von abgestufter monokularer Vernebelung auf die Nystagmusintensität bei Nystagmus latens. Fortschr Ophthalmol 1985;82:303-5.

20. Evans DE, Biglan AW, Todd Troost B. Measurement of visual acuity in latent nystagmus. Ophthalmology 1981;88: 134-7.

21. von Noorden GK. Compensatory mechanisms in congenital nystagmus. Am J Ophthalmol 1987;104:387-97. 